\title{
Impact of advanced maternal age on maternal and neonatal outcomes in preterm birth
}

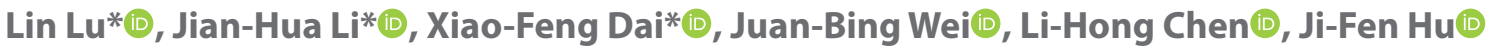 \\ Department of Obstetrics and Gynecology, The First Affiliated Hospital of Fujian Medical University, Fuzhou, China \\ *Equal contributions to this work
}

\begin{abstract}
Objectives: The aim of this study was to investigate the influence of advanced maternal age on the maternal and neonatal outcomes of preterm pregnancies.

Material and methods: The characteristics of patients admitted to the Department of Obstetrics and Gynecology, The First Affiliated Hospital of Fujian Medical University between January 2015 and March, 2019 were retrospectively reviewed. The maternal and neonatal outcomes were compared between advanced maternal age group ( $\geq 35$ years) and younger age group (18-34 years). Statistical analysis was performed by applying the SPSS software.

Results: The study population consisted of 986 pregnancies with preterm delivery and 1094 liveborn preterm infants. Multivariate analyses demonstrated that mothers of advanced age were more likely to suffer iatrogenic preterm birth, placenta previa, preeclampsia, gestational diabetes mellitus and postpartum hemorrhage, but less likely to suffer multiple gestation. In terms of neonatal outcomes, advanced maternal age was associated with a decreased rate of low birthweight in an adjusted model without multiple gestation. However, with multiple gestation included in the adjusted model, advanced maternal age was only associated with an increased rate of hyperbilirubinemia.

Conclusions: Advanced maternal age was a risk factor for adverse pregnancy outcomes including iatrogenic preterm birth, placenta previa, preeclampsia, gestational diabetes mellitus, postpartum hemorrhage, and a protective factor for multiple gestation. Regarding neonatal outcomes, advanced maternal age was related to a decreased rate of low birthweight or an increased rate of hyperbilirubinemia depending on the adjustment for multiple gestation.
\end{abstract}

Key words: advanced maternal age; multiple gestation; preterm birth; pregnancy outcome; preeclampsia

Ginekologia Polska 2022; 93, 2: 134-141

\section{INTRODUCTION}

Conception at an advanced maternal age (35 years or older) has been an increasing trend worldwide over the past decades [1]. In China, the advanced pregnancies increased by over $10 \%$ in the decade from 2004 to 2014 , accounting for about $31 \%$ of total pregnancies in 2016 [2]. Numerous women delay childbearing to achieve their educational and career-related goals. Additionally, the better access to contraception and developments of assisted reproductive technology (ART) also contribute to an increasing incidence of delayed childbearing [3]. Advanced maternal age is related to a range of unfavorable pregnancy outcomes [4]. Several studies demonstrated that women with advanced maternal age in their nulliparous singleton pregnancies were more likely to undergo gestational diabetes mellitus (GDM), gestational hypertension, preeclampsia, cesarean section, small for gestational age infants, and more admission requirement for the neonatal intensive care unit $[5,6]$. In pregnancies by ART or spontaneous conception, advanced maternal age also increased the risk of gestational hypertensive disorders, placenta previa, cesarean delivery, preterm birth, low birthweight, and small for gestational age [3]. Those findings, however, were mainly observed in infants born at term. For premature infants who suffer higher risks for adverse outcomes, the data are scarce and inconsistent according to few studies. The studies by Eventov-Friedman et al. [7] and DiLabio et al. [8] demonstrated that maternal age did not contribute to poor short- and long-term neurodevelopmental outcomes of preterm infants. Whereas Kanungo et al. [9] found an association of advanced maternal age with increased survival without major morbidity and a decreased risk of mortality for preterm newborns.

\section{Corresponding author:}

Lin Lu

Department of Obstetrics and Gynecology, The First Affiliated Hospital of Fujian Medical University, No. 20, Chazhong Road, Taijiang District, Fuzhou 350005, China e-mail:61279109@qq.com; phone: +86059187982052 


\section{Objectives}

In view of the increasing proportion of delayed childbearing, the present study aimed to investigate the impact of advanced maternal age on the short-term outcomes of mothers with preterm delivery and of their premature infants.

\section{MATERIAL AND METHODS}

\section{Study population}

This retrospective study enrolled women who underwent preterm delivery (a gestational age of $<37$ weeks) at the Department of Obstetrics and Gynecology, The First Affiliated Hospital of Fujian Medical University (Fuzhou, China) between January 2015 and March 2019. Maternal and neonatal variables were reviewed from the medical records. The exclusion criteria included maternal age younger than 18 years, induced labor, intrauterine fetal death or stillbirth and missing information of interest. According to the maternal age at delivery, the participants were categorized into the advanced maternal age group (maternal age $\geq 35$ years) and the reference group (maternal age 18-34 years). The maternal and neonatal characteristics were compared between the two groups. The study was accordant with the Declaration of Helsinki and was approved by our institutional review board. Informed consent was obtained from the participants for the use of their records for the evaluation of medical practices.

\section{Variables and definitions}

The maternal characteristics included age, height, body mass index (BMI), education, gravidity, parity, appropriate pregnancy interval (1.5-5 years), prenatal examination, history of premature birth and abortion, method of conception (conception spontaneously or by ART), pre-existing disease (chronic disease prior to the pregnancy) and pregnancy outcomes. Pregnancy outcomes included multiple gestation, gestational age, cause of preterm birth (for spontaneous or iatrogenic reasons), cesarean delivery, placenta previa, placental abruption, intrauterine growth retardation (IUGR, fetal weight below $10^{\text {th }}$ percentile by ultrasound examination), abnormal amniotic fluid volume (amniotic fluid index $\leq 5 \mathrm{~cm}$ or $>20 \mathrm{~cm}$ ), intrahepatic cholestasis of pregnancy (ICP, new onset pruritus and total bile acid level of $\geq 10 \mu \mathrm{mol} / \mathrm{L}$ ), preeclampsia (pregnancy-induced hypertension accompanied by daily proteinuria of $>300 \mathrm{mg}$ ), GDM (positive result of $75 \mathrm{~g}$ oral glucose tolerance test during 24-28 weeks of gestation) and postpartum hemorrhage ( $\mathrm{PPH}$, blood loss of more than $500 \mathrm{ml}$ or $1000 \mathrm{~mL}$ within the first $24 \mathrm{~h}$ after vaginal delivery or caesarean section, respectively).

Neonatal outcomes included sex, birthweight, Apgar scores at 1 and $5 \mathrm{~min}$, neonatal intensive care unit (NICU) admission, neonatal morbidity and mortality. Neonatal mor- bidity included fetal abnormalities, neonatal asphyxia, anemia, hypoglycemia, sepsis, pneumonia, hyperbilirubinemia, hypoxic ischemic encephalopathy (HIE), myocardial damage, and necrotizing enterocolitis. Neonatal asphyxia was defined as oxygen deprivation of organs or brain before, during or just after birth. Anemia was defined as hematocrit $<39 \%$. Neonatal hypoglycemia was defined as plasma glucose concentration of below $45 \mathrm{mg} / \mathrm{dL}$. Neonatal sepsis was defined by positive blood culture results for either bacteria or fungus. Neonatal hyperbilirubinemia was diagnosed based on the serum bilirubin level of more than $10 \mathrm{mg} / \mathrm{dL}$ (171 $\mu \mathrm{mol} / \mathrm{L})$. Hypoxic ischemic encephalopathy was diagnosed based on impaired placental gas exchange complicated by encephalopathy. Myocardial damage was diagnosed based on serum cardiac troponin T of $>0.1 \mu \mathrm{g} / \mathrm{L}$. Necrotizing enterocolitis was defined according to Bell's criteria at stage $\geq 2$ [10]. Neonatal mortality was defined as infant death before hospital discharge.

\section{Statistical analysis}

The statistical analysis was performed using SPSS software version 19.0 (IBM Corp, Armonk, NY, USA). The continuous data were presented as mean \pm standard deviation (SD) and categorical data presented as number (percentage). The $\chi^{2}$ test was employed for the comparison of categorical variables. The normality assessment followed by the Student's t test (data with normal distribution) or the Mann-Whitney $\mathrm{U}$ test (data with skewed distribution) was applied for the comparison of continuous variables. Univariate and multivariate binomial logistic regression analyses were employed to analyze the independent value of advanced maternal age for maternal outcomes which was adjusted for height, BMI, education level, parity, method of conception, pre-existing disease, and for neonatal outcomes which was additionally adjusted for GDM, preeclampsia or multiple gestation. A p-value less than 0.05 was considered statistically significant.

\section{RESULTS}

Maternal and neonatal characteristics of patients

A total of 1014 preterm deliveries occurred in our hospital between January 2015 and March 2019. According to the exclusion criteria, 986 patients were included in the study with 230 (23.33\%) women at the age of $\geq 35$ years and $756(76.67 \%)$ women at the age of 18-34 years. The maternal and neonatal characteristics according to maternal age groups are summarized in Table 1. Mothers in the advanced age group had significantly higher frequency of gravidity and parity, as well as higher proportion of the histories of abortion and pre-existing disease compared to those in the reference group $(p<0.05)$. Whereas mothers of advanced 


\begin{tabular}{|c|c|c|c|c|}
\hline & \multicolumn{2}{|c|}{ Maternal age group } & \multirow[t]{2}{*}{ Statistic value } & \multirow[t]{2}{*}{ p-value } \\
\hline & 18-34 years & $\geq 35$ years & & \\
\hline Maternal, number & $n=756(76.67)$ & $\mathrm{n}=230(23.33)$ & & \\
\hline Age [years] & $28.51 \pm 3.47$ & $37.63 \pm 2.42$ & $Z=-23.03$ & $<0.001$ \\
\hline Height $[\mathrm{cm}]$ & $160.42 \pm 4.59$ & $159.69 \pm 4.17$ & $Z=-2.57$ & 0.010 \\
\hline BMI $\left[\mathrm{kg} / \mathrm{m}^{2}\right]$ & $26.51 \pm 3.34$ & $27.41 \pm 8.03$ & $Z=-1.86$ & 0.063 \\
\hline Education & & & $\chi^{2}=1.25$ & 0.264 \\
\hline High school or less & $389(51.46)$ & $128(55.65)$ & & \\
\hline College or university & $367(48.54)$ & $102(44.35)$ & & \\
\hline Gravidity & & & $Z=-10.36$ & $<0.001$ \\
\hline 1 & $275(36.38)$ & $8(3.48)$ & & \\
\hline 2 & $218(28.84)$ & $67(29.13)$ & & \\
\hline$\geq 3$ & $263(34.78)$ & 155 (67.39) & & \\
\hline Parity & & & $Z=-9.92$ & $<0.001$ \\
\hline 0 & $402(53.17)$ & $35(15.22)$ & & \\
\hline 1 & $306(40.48)$ & 165 (71.74) & & \\
\hline$\geq 2$ & $48(6.35)$ & $30(13.04)$ & & \\
\hline \multicolumn{5}{|l|}{ Appropriate pregnancy interval } \\
\hline Nulliparous & $402(53.17)$ & $35(15.22)$ & & \\
\hline Yes & $222(29.37)$ & $50(21.74)$ & $\chi^{2}=69.12$ & $<0.001$ \\
\hline No & $132(17.46)$ & $145(63.04)$ & & \\
\hline Regular prenatal examination & $650(85.98)$ & $184(80.00)$ & $\chi^{2}=4.83$ & 0.028 \\
\hline History of premature birth & $25(3.31)$ & $14(6.09)$ & $\chi^{2}=3.59$ & 0.058 \\
\hline History of abortion & $316(41.80)$ & $162(70.43)$ & $\chi^{2}=57.90$ & $<0.001$ \\
\hline Use of ART & $46(6.08)$ & $19(8.26)$ & $\chi^{2}=1.36$ & 0.244 \\
\hline Pre-existing disease & $208(27.51)$ & $82(35.65)$ & $\chi^{2}=5.63$ & 0.018 \\
\hline Neonatal, number & $\mathrm{n}=848(77.51)$ & $n=246(22.49)$ & & \\
\hline Sex, male & 479 (56.49) & $135(54.88)$ & $\chi^{2}=0.20$ & 0.655 \\
\hline Birthweight [g] & $2281.47 \pm 607.62$ & $2312.76 \pm 712.14$ & $Z=-1.20$ & 0.232 \\
\hline Apgar score at $1 \mathrm{~min}$ & $8.89 \pm 2.12$ & $8.72 \pm 1.99$ & $Z=-1.46$ & 0.143 \\
\hline Apgar score at $5 \mathrm{~min}$ & $9.57 \pm 1.27$ & $9.52 \pm 1.30$ & $Z=-0.58$ & 0.561 \\
\hline NICU stay [days] & $12.84 \pm 15.14$ & $12.92 \pm 17.40$ & $Z=-1.00$ & 0.320 \\
\hline
\end{tabular}

*Data are presented as number (percentage) or mean \pm standard deviation; ART — assisted reproductive technology; BMI — body mass index; NICU — neonatal intensive care unit

age were less likely to have higher height as well as to undergo appropriate pregnancy interval and regular prenatal examination than those of younger age $(p<0.05)$. There were a total of 1094 live births, with 246 preterm infants born to mothers of advanced age and 848 preterm infants born to mothers aged 18-34 years. There was no significant difference regarding neonatal sex, birthweight, Apgar scores at 1 and 5 min, and NICU stay between the 2 groups.

\section{Impact of advanced maternal age on maternal outcomes}

The impact of advanced maternal age on pregnancy outcomes is shown in Table 2 and 3. Compared to women with 18-34 years of age, women aged $\geq 35$ years had significantly decreased proportion of multiple gestation and spontaneous preterm birth but increased proportion of iatrogenic preterm birth and cesarean delivery $(p<0.05)$. Moreover, pregnancy complications including placenta previa, preeclampsia, GDM, and PPH were more frequently seen in women with advanced age than in women with 18-34 years of age ( $p<0.001$ ) (Tab. 2). Based on the results of unadjusted logistic regression analysis (Tab. 3), the incidences of pregnancy outcomes including iatrogenic preterm birth, cesarean delivery, placenta previa, preeclampsia, GDM and PPH were more likely in mothers with advanced age, whereas multiple gestation was less likely to 


\begin{tabular}{|c|c|c|c|c|c|}
\hline & \multirow[t]{2}{*}{ Total $(n=986)$} & \multicolumn{2}{|c|}{ Maternal age group } & \multirow[t]{2}{*}{$c^{2}$} & \multirow[t]{2}{*}{ p-value } \\
\hline & & $18-34$ years $(n=756)$ & $\geq 35$ years $(n=230)$ & & \\
\hline Multiple gestation & $111(11.26)$ & $94(12.43)$ & $17(7.39)$ & 4.49 & 0.042 \\
\hline Gestational age & & & & 0.44 & 0.514 \\
\hline 28 to $<32$ weeks & $137(13.89)$ & $102(13.49)$ & $35(15.22)$ & & \\
\hline 32 to $<37$ weeks & $849(86.11)$ & $654(86.51)$ & 195 (84.78) & & \\
\hline Cause of preterm birth & & & & 25.31 & $<0.001$ \\
\hline Spontaneous reason & $499(50.61)$ & $416(55.03)$ & $83(36.09)$ & & \\
\hline latrogenic reason & $487(49.39)$ & $340(44.97)$ & $147(63.91)$ & & \\
\hline Cesarean delivery & $715(72.52)$ & $524(69.31)$ & $191(83.04)$ & 16.68 & $<0.001$ \\
\hline Placenta previa & $164(16.63)$ & $104(13.76)$ & $60(26.09)$ & 19.34 & $<0.001$ \\
\hline Placental abruption & $51(5.17)$ & $39(5.16)$ & $12(5.22)$ & $<0.01$ & 1.000 \\
\hline Intrauterine growth retardation & $155(15.72)$ & $117(15.48)$ & $38(16.52)$ & 0.66 & 0.458 \\
\hline Abnormal amniotic fluid volume & $42(4.26)$ & $33(4.37)$ & $9(3.91)$ & 0.09 & 0.854 \\
\hline Intrahepatic cholestasis of pregnancy & $48(4.87)$ & $38(5.03)$ & $10(4.35)$ & 0.18 & 0.731 \\
\hline Preeclampsia & $178(18.05)$ & $118(15.61)$ & $60(26.09)$ & 13.09 & $<0.001$ \\
\hline Gestational diabetes mellitus & $169(17.14)$ & $107(14.15)$ & $62(26.96)$ & 20.35 & $<0.001$ \\
\hline Postpartum hemorrhage & $88(8.92)$ & $52(6.88)$ & $36(15.65)$ & 16.70 & $<0.001$ \\
\hline
\end{tabular}

*Data are presented as number (percentage)

Table 3. Impact of advanced maternal age on pregnancy outcomes by the univariate and multivariate analyses

\begin{tabular}{|c|c|c|c|c|}
\hline & \multicolumn{4}{|c|}{$\geq 35$ years } \\
\hline & Crude OR (95\% Cl) & p-value & Adjusted OR ${ }^{\mathrm{a}}(95 \% \mathrm{Cl})$ & p-value \\
\hline Multiple gestation & $0.56(0.33-0.96)$ & 0.036 & $0.33(0.16-0.64)$ & 0.001 \\
\hline Gestational age (very preterm) & $0.87(0.57-1.32)$ & 0.508 & $0.88(0.56-1.38)$ & 0.578 \\
\hline latrogenic preterm birth & $2.17(1.60-2.94)$ & $<0.001$ & $1.65(1.18-2.31)$ & 0.004 \\
\hline Cesarean delivery & $2.17(1.49-3.16)$ & $<0.001$ & $1.50(0.99-2.27)$ & 0.055 \\
\hline Placenta previa & $2.21(1.54-3.17)$ & $<0.001$ & $1.64(1.11-2.43)$ & 0.013 \\
\hline Placental abruption & $1.01(0.52-1.97)$ & 0.972 & $1.11(0.54-2.27)$ & 0.776 \\
\hline Intrauterine growth retardation & $1.08(0.73-1.61)$ & 0.703 & $1.32(0.85-2.04)$ & 0.219 \\
\hline Abnormal amniotic fluid volume & $0.89(0.42-1.89)$ & 0.766 & $0.81(0.37-1.79)$ & 0.602 \\
\hline Intrahepatic cholestasis of pregnancy & $0.86(0.42-1.75)$ & 0.676 & $0.75(0.35-1.62)$ & 0.465 \\
\hline Preeclampsia & $1.91(1.34-2.72)$ & $<0.001$ & $1.98(1.32-2.96)$ & 0.001 \\
\hline Gestational diabetes mellitus & $2.24(1.57-3.20)$ & $<0.001$ & $2.44(1.65-3.61)$ & $<0.001$ \\
\hline Postpartum hemorrhage & $2.51(1.60-3.96)$ & $<0.001$ & $1.89(1.16-3.08)$ & 0.011 \\
\hline
\end{tabular}

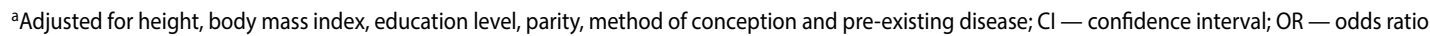

be seen in the older mothers. After adjusting for the potential confounders (Tab. 3), the differences regarding multiple gestation [adjusted odds ratio (OR) $0.33,95 \%$ confidence interval (Cl) 0.16-0.64], iatrogenic preterm birth (adjusted OR 1.65, 95\% Cl 1.18-2.31), placenta previa (adjusted OR $1.64,95 \% \mathrm{Cl} 1.11-2.43$ ), preeclampsia (adjusted OR 1.98, 95\% Cl 1.32-2.96), GDM (adjusted OR 2.44, 95\% Cl 1.65-3.61) and $\mathrm{PPH}$ (adjusted OR $1.89,95 \% \mathrm{Cl} 1.16-3.08$ ) remained statically significant, with the cesarean delivery near a significant level (adjusted OR 1.50, 95\% Cl 0.99-2.27).

\section{Impact of advanced maternal age on neonatal outcomes}

The impact of advanced maternal age on neonatal outcomes is shown in Table 4 and 5. The rates of hyperbilirubinemia, NICU admission and neonatal mortality were more 


\begin{tabular}{|c|c|c|c|c|c|}
\hline & Total $(n=1094)$ & $18-34$ years $(n=848)$ & $\geq 35$ years $(n=246)$ & $c^{2}$ & p-value \\
\hline Low birthweight $<2500 \mathrm{~g}$ & $620(56.67)$ & $494(58.25)$ & $126(51.22)$ & 3.84 & 0.050 \\
\hline Apgar score $<7 / 1 \mathrm{~min}$ & $104(9.51)$ & $76(8.96)$ & $28(11.38)$ & 1.30 & 0.255 \\
\hline Apgar score $<7 / 5 \mathrm{~min}$ & $30(2.74)$ & $23(2.71)$ & $7(2.95)$ & 0.02 & 0.895 \\
\hline Fetal abnormalities & $61(5.58)$ & $46(5.54)$ & $15(6.10)$ & 0.16 & 0.685 \\
\hline Asphyxia & $186(17.00)$ & $135(15.92)$ & $51(20.73)$ & 3.13 & 0.077 \\
\hline Anemia & $218(19.93)$ & $163(19.22)$ & $55(20.36)$ & 1.18 & 0.278 \\
\hline Hypoglycemia & $313(28.61)$ & $245(28.89)$ & $68(27.64)$ & 0.15 & 0.703 \\
\hline Sepsis & $167(15.27)$ & $126(14.86)$ & $41(16.67)$ & 0.48 & 0.488 \\
\hline Pneumonia & $117(10.69)$ & $91(10.73)$ & $26(10.57)$ & 0.01 & 0.942 \\
\hline Hyperbilirubinemia & $817(74.68)$ & $616(72.64)$ & $201(81.71)$ & 8.29 & 0.004 \\
\hline Hypoxic ischemic encephalopathy & $12(1.10)$ & $9(1.06)$ & $3(1.22)$ & 0.04 & 0.834 \\
\hline Myocardial damage & $403(36.84)$ & $318(37.50)$ & $85(34.55)$ & 0.71 & 0.399 \\
\hline Necrotizing enterocolitis & $26(2.38)$ & $20(2.36)$ & $6(2.44)$ & 0.01 & 0.942 \\
\hline NICU admission & $906(82.82)$ & $691(81.49)$ & $215(87.40)$ & 4.68 & 0.030 \\
\hline Neonatal mortality & $26(2.38)$ & $16(1.89)$ & $10(4.07)$ & 3.90 & 0.048 \\
\hline
\end{tabular}

*Data are presented as number (percentage); NICU — neonatal intensive care unit

Table 5. Impact of advanced maternal age on neonatal outcomes by the univariate and multivariate analyses

\begin{tabular}{|c|c|c|c|c|c|c|}
\hline & \multicolumn{6}{|c|}{$\geq 35$ years } \\
\hline & Crude OR (95\% Cl) & $p$-value & Adjusted OR ${ }^{\mathrm{a}}(95 \% \mathrm{Cl})$ & p-value & Adjusted OR ${ }^{b}(95 \% \mathrm{Cl})$ & p-value \\
\hline Low birthweight $<2500 \mathrm{~g}$ & $0.75(0.57-1.00)$ & 0.050 & $0.68(0.49-0.93)$ & 0.017 & $0.77(0.55-1.07)$ & 0.113 \\
\hline Apgar score $<7 / 1 \mathrm{~min}$ & $1.31(0.83-2.06)$ & 0.256 & $1.14(0.69-1.90)$ & 0.611 & $1.10(0.66-1.83)$ & 0.723 \\
\hline Apgar score $<7 / 5 \mathrm{~min}$ & $1.05(0.45-2.48)$ & 0.910 & $0.80(0.31-2.07)$ & 0.644 & $0.76(0.30-1.98)$ & 0.580 \\
\hline Fetal abnormalities & $1.13(0.62-2.07)$ & 0.686 & $1.05(0.55-2.02)$ & 0.878 & $1.05(0.55-2.04)$ & 0.875 \\
\hline Asphyxia & $1.38(0.97-1.98)$ & 0.078 & $1.24(0.84-1.84)$ & 0.282 & $1.20(0.81-1.78)$ & 0.374 \\
\hline Anemia & $1.21(0.86-1.71)$ & 0.279 & $1.12(0.77-1.64)$ & 0.549 & $1.20(0.82-1.77)$ & 0.343 \\
\hline Hypoglycemia & $0.94(0.69-1.29)$ & 0.703 & $0.81(0.57-1.14)$ & 0.230 & $0.83(0.59-1.18)$ & 0.305 \\
\hline Sepsis & $1.15(0.78-1.68)$ & 0.488 & $1.14(0.75-1.74)$ & 0.529 & $1.17(0.77-1.79)$ & 0.455 \\
\hline Pneumonia & $0.98(0.62-1.56)$ & 0.942 & $0.85(0.51-1.40)$ & 0.518 & $0.87(0.52-1.45)$ & 0.593 \\
\hline Hyperbilirubinemia & $1.68(1.18-2.40)$ & 0.004 & $1.45(0.99-2.12)$ & 0.060 & $1.48(1.01-2.18)$ & 0.047 \\
\hline Hypoxic ischemic encephalopathy & $1.15(0.31-4.28)$ & 0.834 & $1.27(0.30-5.43)$ & 0.744 & $1.13(0.26-5.00)$ & 0.868 \\
\hline Myocardial damage & $0.88(0.65-1.19)$ & 0.399 & $0.86(0.62-1.18)$ & 0.343 & $0.88(0.64-1.22)$ & 0.437 \\
\hline Necrotizing enterocolitis & $1.04(0.41-2.61)$ & 0.942 & $1.26(0.45-3.47)$ & 0.662 & $1.38(0.50-3.84)$ & 0.538 \\
\hline NICU admission & $1.58(1.04-2.39)$ & 0.032 & $1.28(0.81-2.00)$ & 0.289 & $1.35(0.86-2.12)$ & 0.197 \\
\hline Neonatal mortality & $2.20(0.99-4.92)$ & 0.054 & $2.23(0.91-5.47)$ & 0.078 & $2.30(0.93-5.71)$ & 0.072 \\
\hline
\end{tabular}

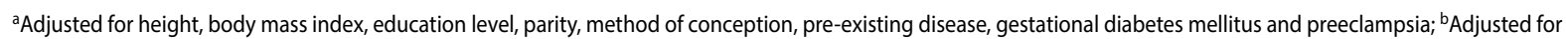
the above factors and multiple gestation; $\mathrm{Cl}$ - confidence interval; $\mathrm{NICU}$ - neonatal intensive care unit; $\mathrm{OR}$ - odds ratio

common in the advanced maternal age group compared with the reference group $(p<0.05)$. The rates of other neonatal outcomes were similar between the two groups (Tab. 4). According to the results of unadjusted logistic regression analysis (Tab. 5), advanced maternal age was significantly associated with higher incidences of hyperbilirubinemia and NICU admission. After adjusting for the potential confound- ers including height, BMI, education level, parity, method of conception, pre-existing disease, GDM and preeclampsia, however, the association of advanced maternal age with a decreased rate of low birthweight (adjusted OR 0.68, 95\% $\mathrm{Cl}$ 0.49-0.93) was significant. The association of advanced maternal age with increased rates of hyperbilirubinemia (adjusted OR 1.45, 95\% Cl 0.99-2.12) and neonatal mortal- 
ity (adjusted OR 2.23, 95\% Cl 0.91-5.47) was marginally significant. With multiple gestation included in the adjusted model, the association of advanced maternal age with an increased rate of hyperbilirubinemia (adjusted OR 1.48, 95\% $\mathrm{Cl}$ 1.01-2.18) was statistically significant, whereas the difference of low birthweight (adjusted OR 0.77, 95\% Cl 0.55-1.07) between maternal age groups was not statistically significant. There was no significant difference between the two groups regarding the rates of other neonatal outcomes in the two adjusted models.

\section{DISCUSSION}

Delayed childbearing is increasingly common over the past decades, which is regarded as a risk factor for adverse maternal and perinatal outcomes [11]. The present study found that, with the potential confounders controlled, mothers giving birth at an advanced age were more likely to undergo iatrogenic preterm birth, placenta previa, preeclampsia, GDM, PPH but less likely to undergo multiple gestation. Regarding the neonatal outcomes, there was a significant association of advanced maternal age with a decreased rate of low birthweight after controlling for the confounders without multiple gestation. However, with the multiple gestation adjusted, advanced maternal age was only associated with an increased risk of hyperbilirubinemia.

Tseng et al. [12] found an association of advanced maternal age with preeclampsia by univariable analysis. The present study, after adjustment for main confounding factors, observed the independent role of maternal age for preeclampsia. Women of advanced maternal age were approximately 2.0 times more likely to suffer preeclampsia than those under 35 years of age (Tab. 3). The proper explanation could be that aging promotes vascular pathologies including endothelial dysfunction and pathological remodeling of the microcirculation, which characterize preeclampsia [13]. Aging-associated vascular dysfunctions and vasculopathies are also hallmarks of diabetes [14]. According to our results, GDM was almost twice $(27 \%$ and $14 \%$, respectively) as common in women aged $\geq 35$ years compared with women aged $<35$ years. Moreover, the positive association of maternal age with GDM in preterm pregnancies remained significant even after adjustment for main potential confounders, which was consistent with the previous study by Lai et al. [15].

Placenta previa is an unfrequently seen complication which occurs to $0.4-3.2 \%$ of pregnancies $[3,16,17]$. Tseng et al. [12] found no effect of advanced maternal age on placenta previa by univariate analysis in a cohort of very low birthweight preterm infants. The present study, however, found that placenta previa was approximately 2 times more prevalent for mothers aged $\geq 35$ years than that for mother aged below 35 years (Tab. 2). With adjustment for main confounders, advanced maternal age remained an independent contributing factor for placenta previa with an adjusted odds ratio of 1.64, which was in accordance with one previous report [16]. That can be partially explained by atherosclerosis-induced vascular endothelial dysfunction of the uterus, leading to insufficient perfusion of the placenta. As a result, the placenta tends to implant in the lower uterine segment, thereby increasing the risk of placenta previa [18].

According to Schummers et al. [19], the risk of iatrogenic preterm delivery increased independently with maternal age, especially for those $\geq 35$ years. Consistently, the present study demonstrated that advanced maternal age was a risk factor for iatrogenic preterm delivery, independent of height, BMI, education level, parity, method of conception and pre-existing disease. Among iatrogenic preterm births, preeclampsia was reported to be the most common indication [20]. Placental implantation abnormalities, especially for placenta previa, are also the major contributors to medically indicated preterm delivery [21]. The development of those pregnancy complications in advanced-maternal-age women, is mainly attributed to placental insufficiency, as demonstrated by lower placental weight-to-birth weight ratios, decreased uteroplacental spiral vasculature volume and abnormal placental-derived hormones and biomarkers [22].

Women of advanced age are more likely to undergo cesarean section [23] and PPH [24]. The present study found that advanced maternal age was an independent risk factor for PPH and a marginally independent risk factor for cesarean section. Decreased number of oxytocin receptors and maternal complications such as preeclampsia and GDM with age are the proposed causes of cesarean section and $\mathrm{PPH}[16,25]$. Magnesium sulfate, a routine medicine for patients with preeclampsia, also has the side effect of compromising postpartum uterine contractility [26]. As a result of prolonged labor, cesarean delivery is often performed, leading to uterine muscle fatigue or damaged contraction at the uterine incision site, and eventually making a patient susceptible to uterine atony. Moreover, preeclampsia may lead to thrombocytopenia, platelet dysfunction, and disseminated intravascular coagulation [26]. Under these conditions, mothers of advanced maternal age are relatively vulnerable to $\mathrm{PPH}$.

In this study, the impact of advanced maternal age on short-term neonatal outcomes was also evaluated. With adjustment for height, BMI, education level, parity, method of conception, pre-existing disease, GDM and preeclampsia, mothers of advanced age were less likely to deliver infants with low birth weight. However, with multiple gestation included in the above adjusted model, only the association of advanced maternal age with hyperbilirubinemia 
was found. Previous studies have reported that advanced maternal age was not associated with adverse neonatal outcomes in the cohort of preterm infants, with limited controlling of the potential confounding $[7,12]$. This study, after adjusting for more possible factors including multiple gestation, further demonstrated the not significant impact of advanced maternal age on neonatal outcomes except for hyperbilirubinemia. Research regarding the impact of maternal age on neonatal hyperbilirubinemia are limited. Our results were consistent with the study by Boskabadi et al. [27], which demonstrated that maternal age above 35 years during pregnancy is a maternal risk factor for neonatal hyperbilirubinemia.

There remains controversial regarding the effect of advanced maternal age on the birthweight of infants, depending on the controlling of the confounders. According to the unadjusted analysis by DiLabio et al. [8], the birthweight in pregnancies of mothers aged $\geq 35$ years was not significantly different compared with mothers aged 20-34 years in a cohort of preterm infants with < 29-week gestation. Adane et al. [28] reported a significant association of maternal age $\geq 35$ years with low birthweight, after controlling for the potential confounders. However, the status of multiple gestation was not included in the adjusted model. In the present study, multiple gestation was identified as a considerable factor in the association between advanced maternal age and low birth weight. Similarly, Simchen et al. [29] reported that the association of advanced maternal age with low birth weight was primarily attributed to multiple gestation. Among cohorts of singleton pregnancies, multiple analysis found no significant difference regarding the rate of low birthweight infants between advanced and younger ages $[2,6,16]$. Mothers with advanced maternal age tend to have higher educational and socioeconomic statuses, which may be related to less common maternal obesity and fetal macrosomia. That may help to explain the not increased birth weight in the older mothers [30].

There are several limitations in our study. Firstly, random bias may exist due to the retrospective nature and the relatively small sample size in a single center population. Secondly, though our study controlled common maternal characteristics, some degree of undetermined confounding is possible owing to the missing capture of other sociodemographic factors (i.e., socioeconomic status) that affect perinatal outcome. Thirdly, the study only investigated the effect of advanced maternal age on the neonatal short-term complications. Long-term follow-up regarding the neurodevelopmental status is required to comprehensively evaluate the impact of advanced maternal age on the outcomes of preterm birth infants. Despite of those limitations, the findings of our study are strengthened by the selection of population with preterm delivery and the ability to control for multiple gestation apart from common risk factors in the analysis of neonatal outcomes in this preterm population.

\section{CONCLUSIONS}

In a preterm infant population, advanced maternal age was a risk factor for adverse pregnancy outcomes including iatrogenic preterm birth, placenta previa, preeclampsia, $\mathrm{GDM}, \mathrm{PPH}$, and a protective factor for multiple gestation. In terms of neonatal outcomes, advanced maternal age was associated with a decreased rate of low birthweight or an increased rate of hyperbilirubinemia according to the independence of multiple gestation. Multiple gestation should be considered in the analysis of the risk factors for neonatal outcomes in the cohort of preterm infants. Timely diagnosis of those complications to take maternal monitoring and better management is warranted to improve pregnancy outcomes for women conceived at an advanced age.

\section{Acknowledgements}

LL: conception, study design, manuscript draft and corresponding author; JHL and XFD: data interpretation and critical revision of the manuscript; JBW: data acquisition; LHC and JFH: data process and statistical analysis.

\section{Funding}

This work was supported by the Fujian Provincial Department of Science and Technology Project under Grant number: 2017 Y0034.

\section{Conflict of interest}

All authors declare no conflict of interest.

\section{REFERENCES}

1. Lean SC, Derricott H, Jones RL, et al. Advanced maternal age and adverse pregnancy outcomes: a systematic review and meta-analysis. PLoS One. 2017; 12(10): e0186287, doi: 10.1371/journal.pone.0186287, indexed in Pubmed: 29040334.

2. Shan D, Qiu PY, Wu YX, et al. Pregnancy outcomes in women of advanced maternal age: a retrospective cohort study from China. Sci Rep. 2018; 8(1): 12239, doi: 10.1038/s41598-018-29889-3, indexed in Pubmed: 30115949.

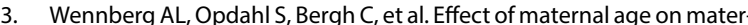
nal and neonatal outcomes after assisted reproductive technology. Fertil Steril. 2016; 106(5): 1142-1149.e14, doi: 10.1016/j.fertnstert.2016.06.021, indexed in Pubmed: 27399261.

4. Kenny LC, Lavender T, McNamee R, et al. Advanced maternal age and adverse pregnancy outcome: evidence from a large contemporary cohort. PLoS One. 2013; 8(2): e56583, doi: 10.1371/journal.pone.0056583, indexed in Pubmed: 23437176.

5. Pinheiro RL, Areia AL, Mota Pinto A, et al. Advanced maternal age: adverse outcomes of pregnancy, a meta-analysis. Acta Med Port. 2019; 32(3): 219-226, doi: 10.20344/amp.11057, indexed in Pubmed: 30946794.

6. Kahveci B, Melekoglu R, Evruke IC, et al. The effect of advanced maternal age on perinatal outcomes in nulliparous singleton pregnancies. BMC Pregnancy Childbirth. 2018; 18(1): 343, doi: 10.1186/s12884-018-1984-x, indexed in Pubmed: 30134873.

7. Eventov-Friedman S, Zisk-Rony RY, Nosko S, et al. Maternal age and outcome of preterm infants at discharge from the neonatal intensive care unit. Int J Gynaecol Obstet. 2016; 132(2): 196-199, doi: 10.1016/j. ijgo.2015.06.052, indexed in Pubmed: 26476582. 
8. DiLabio J, Zwicker JG, Sherlock R et al. Canadian Neonatal Network and Canadian Neonatal Follow-Up Network. Maternal age and long-term neurodevelopmental outcomes of preterm infants $<29$ weeks gestational age. J Perinatol. 2021; 41(6): 1304-1312, doi: 10.1038/s41372020-0735-9, indexed in Pubmed: 32694856.

9. Kanungo J, James A, McMillan D, et al. Canadian Neonatal Network. Advanced maternal age and the outcomes of preterm neonates: a social paradox? Obstet Gynecol. 2011; 118(4): 872-877, doi: 10.1097/AOG.0b013e31822add60, indexed in Pubmed: 21934451.

10. Bell MJ, Ternberg JL, Feigin RD, et al. Neonatal necrotizing enterocolitis. Therapeutic decisions based upon clinical staging. Ann Surg. 1978; 187(1): 1-7, doi: 10.1097/00000658-197801000-00001, indexed in Pubmed: 413500

11. Carolan M. Maternal age $\geq 45$ years and maternal and perinatal outcomes: a review of the evidence. Midwifery. 2013; 29(5): 479-489, doi: 10.1016/j.midw.2012.04.001, indexed in Pubmed: 23159159.

12. Tseng KT, Peng CC, Chang JH, et al. The impact of advanced maternal age on the outcomes of very low birth weight preterm infants. Medicine (Baltimore). 2019; 98(5): e14336, doi: 10.1097/MD.0000000000014336, indexed in Pubmed: 30702619.

13. Ungvari Z, Tarantini S, Kiss T, et al. Endothelial dysfunction and angiogenesis impairment in the ageing vasculature. Nat Rev Cardiol. 2018; 15(9): 555-565, doi: 10.1038/s41569-018-0030-z, indexed in Pubmed: 29795441.

14. Sawada N, Arany Z. Metabolic regulation of angiogenesis in diabetes and aging. Physiology (Bethesda). 2017; 32(4): 290-307, doi: 10.1152/physiol.00039.2016, indexed in Pubmed: 28615313.

15. Lai FY, Johnson JA, Dover D, et al. Outcomes of singleton and twin pregnancies complicated by pre-existing diabetes and gestational diabetes: a population-based study in Alberta, Canada, 2005-11. J Diabetes. 2016; 8(1): 45-55, doi: 10.1111/1753-0407.12255, indexed in Pubmed: 25496644.

16. Claramonte Nieto M, Meler Barrabes E, Garcia Martínez S, et al. Impact of aging on obstetric outcomes: defining advanced maternal age in BarceIona. BMC Pregnancy Childbirth. 2019; 19(1): 342, doi: 10.1186/s12884019-2415-3, indexed in Pubmed: 31547808.

17. Wittmaack A, Dudley D, Boyle A. Maternal history of cervical surgery and preterm delivery: a retrospective cohort study. J Womens Health (Larchmt). 2019; 28(11): 1538-1542, doi: 10.1089/jwh.2018.7457, indexed in Pubmed: 31730425.

18. Martinelli KG, Garcia ÉM, Santos Neto ET, et al. Advanced maternal age and its association with placenta praevia and placental abruption: a meta-analysis. Cad Saude Publica. 2018; 34(2): e00206116, doi: 10.1590/0102-311X00206116, indexed in Pubmed: 29489954.
19. Schummers L, Hutcheon JA, Hacker MR, et al. Absolute risks of obstetric outcomes by maternal age at first birth: a population-based cohort. Epidemiology. 2018; 29(3):379-387, doi: 10.1097/EDE.0000000000000818, indexed in Pubmed: 29517506.

20. Ananth CV, Vintzileos AM. Maternal-fetal conditions necessitating a medical intervention resulting in preterm birth. Am J Obstet Gynecol. 2006; 195(6): 1557-1563, doi: 10.1016/j.ajog.2006.05.021, indexed in Pubmed: 17014813.

21. Vahanian SA, Lavery JA, Ananth CV, et al. Placental implantation abnormalities and risk of preterm delivery: a systematic review and metaanalysis. Am J Obstet Gynecol. 2015; 213(4 Suppl): S78-S90, doi: 10.1016/j.ajog.2015.05.058, indexed in Pubmed: 26428506.

22. Cooke CLM, Davidge ST. Advanced maternal age and the impact on maternal and offspring cardiovascular health. Am J Physiol Heart Circ Physiol. 2019; 317(2): H387-H394, doi: 10.1152/ajpheart.00045.2019, indexed in Pubmed: 31199185.

23. Khalil A, Syngelaki A, Maiz N, et al. Maternal age and adverse pregnancy outcome: a cohort study. Ultrasound Obstet Gynecol. 2013; 42(6): 634-643, doi: 10.1002/uog.12494, indexed in Pubmed: 23630102.

24. Blomberg M. Maternal obesity and risk of postpartum hemorrhage. Obstet Gynecol. 2011; 118(3):561-568, doi: 10.1097/AOG.0b013e31822a6c59, indexed in Pubmed: 21860284.

25. Blitz MJ, Yukhayev A, Pachtman SL, et al. Twin pregnancy and risk of postpartum hemorrhage. J Matern Fetal Neonatal Med. 2020; 33(22): 3740-3745, doi: 10.1080/14767058.2019.1583736, indexed in Pubmed: 30836810.

26. Bateman BT, Berman MF, Riley LE, et al. The epidemiology of postpartum hemorrhage in a large, nationwide sample of deliveries. Anesth Analg. 2010; 110(5): 1368-1373, doi: 10.1213/ANE.0b013e3181d74898, indexed in Pubmed: 20237047.

27. Boskabadi $\mathrm{H}$, Rakhshanizadeh F, Zakerihamidi M. Evaluation of maternal risk factors in neonatal hyperbilirubinemia. Arch Iran Med. 2020; 23(2): 128-140, indexed in Pubmed: 32061076.

28. Adane T, Dachew BA. Low birth weight and associated factors among singleton neonates born at Felege Hiwot referral hospital, North West Ethiopia. Afr Health Sci. 2018; 18(4): 1204-1213, doi: 10.4314/ahs. v18i4.42, indexed in Pubmed: 30766587.

29. Simchen MJ, Shulman A, Wiser A, et al. The aged uterus: multifetal pregnancy outcome after ovum donation in older women. Hum Reprod. 2009; 24(10): 2500-2503, doi: 10.1093/humrep/dep238, indexed in Pubmed: 19581283.

30. Treacy A, Robson M, O'Herlihy C. Dystocia increases with advancing maternal age. Am J Obstet Gynecol. 2006; 195(3): 760-763, doi: 10.1016/j. ajog.2006.05.052, indexed in Pubmed: 16949410. 